\title{
Inhibitory Effects of Mas-Related Gene C Receptor on Chronic Morphine-Induced Spinal Glial Activation in Rats
}

\author{
Yunshan Zhang, Mei Wang, Qiuhua Lu, Qi Li, Mingyan Lin, Jianzhong Huang, \\ and Yanguo Hong \\ Provincial Key Laboratory of Developmental Biology and Neuroscience, Fujian Normal University, Fuzhou, Fujian, China
}

Received July 29, 2018; accepted November 20, 2018

\begin{abstract}
Glial activation plays a pivotal role in morphine tolerance. This study investigated effects of Mas-related gene (Mrg) C receptor on morphine-induced activation of microglia and astrocytes in the spinal cord and its underlying mechanisms. Intrathecal administration of morphine (20 $\mu \mathrm{g}$, daily) for 6 days induced a great decline in morphine antinociception and increased expression of glial fibrillary acidic protein and OX-42 in the spinal dorsal horn. These changes were greatly attenuated by the intermittent coinjection of bovine adrenal medulla 8-22 (BAM8-22, $1 \mathrm{nmol})$, a specific agonist of $\mathrm{MrgC}$ receptor. These modulatory effects were accompanied by the reduction of $\mathrm{P}_{2} \mathrm{X}_{4}$ and interleukin-1 $\beta$ expressions in the spinal dorsal horn. Chronic morphine increased the expression of fractalkine in medium- and small-
\end{abstract}

\section{Introduction}

The repeated administration of opioids results in the development of tolerance and hyperalgesia, limiting opioid efficacy in the clinical treatment of pain. There is growing evidence that spinal cord microglia and astrocytes play a central role in the development and maintenance of morphine (prototypical opioid) tolerance (Watkins et al., 2009). Astrocytes and microglia are in close contact with neuronal somas in the spinal dorsal horn (Haydon, 2001) and express many functional molecules (Porter and McCarthy, 1997; Pocock and Kettenmann, 2007). Following chronic exposure to morphine, spinal glial cells are activated, which manifests as cell hypertrophy, retraction of processes, an increase in the cell density, and expression of OX-42 (Raghavendra et al., 2002) or glial fibrillary acidic protein (GFAP) (Tawfik et al., 2005). Activated microglia and astrocytes display functional changes. It has been shown that purinergic $\mathrm{P}_{2} \mathrm{X}_{4}$ receptor (Horvath et al., 2010) and interleukin-1 $\beta$ (IL-1 $\beta$ ) (Johnston et al., 2004) are upregulated in spinal glial cells following repeated morphine administration. $\mathrm{P}_{2} \mathrm{X}_{4}$ receptor activates microglia and astrocytes

Research was funded by the Natural Science Foundation of China [Grants 31371124 and 81571084$]$. None of the authors has a conflict of interest.

https://doi.org/10.1124/jpet.118.252494. sized neurons of dorsal root ganglia (DRG). Treatment with BAM8-22 inhibited these changes as well as an increase in Tolllike receptor 4 (TLR4) protein in DRG. Chronic treatment of DRG explant cultures with morphine ( $3.3 \mu \mathrm{M}, 5$ days) increased the levels of fractalkine mRNA. Application of BAM8-22 (10 nM) for 60 minutes completely blocked the increase of fractalkine mRNA induced by morphine. Our findings indicate that the inhibition of morphine tolerance by $\mathrm{MrgC}$ receptor was associated with the modulation of astrocytes and microglia in the spinal dorsal horn and fractalkine and TLR4 expressions in DRG. As MrgC receptor is exclusively located in DRG, intermittent combination of MrgC receptor agonist could be a promising adjunct with limited side effects for chronic use of opiates.

ABBREVIATIONS: BAM8-22, bovine adrenal medulla 8-22; DMEM, Dulbecco's modified Eagle's medium; DRG, dorsal root ganglia; GAPDH, glyceraldehyde-3-phosphate-dehydrogenase; GFAP, glial fibrillary acidic protein; IL-1 $\beta$, interleukin- $1 \beta$; i.t., intrathecally; MOR, $\mu$-opioid receptor; MPE, maximum possible effect; Mrg, Mas-related gene; OX-42, integrin $\alpha$ M antibody; $\mathrm{P}_{2} \mathrm{X}_{4}, \mathrm{P} 2 \mathrm{X}$ purinoceptor 4; PBS, phosphate-buffered saline; TFL, tail flick latency; TLR4, Toll-like receptor 4. 
the function and characterization of rat $\mathrm{MrgC}$ receptor. It has been demonstrated that activation of $\mathrm{MrgC}$ receptor protects against (Liu et al., 2009; He et al., 2014a) and inhibits (Jiang et al., 2013; He et al., 2014b) pain hypersensitivity induced by nerve injury and inflammation in the periphery. However, $\mathrm{MrgC}$ receptor does not play a role in pain processing in the normal condition, as evidenced by the studies showing that intrathecal (i.t.) administration of bovine adrenal medulla 8-22 (BAM8-22) in rats (Cai et al., 2007; Chen et al., 2010) and mice (Guan et al., 2010) does not change pain sensitivity. BAM8-22 is an analog of the endogenous opioid peptide BAM22 (Lembo et al., 2002), a cleavage product of proenkephalin A (precursor of Leu- and Met-enkephalin) in the adrenal medulla (Davis et al., 1990). However, BAM8-22 does not activate opioid receptors and displays high affinity with $\mathrm{MrgC}$ receptor (Lembo et al., 2002). It is a highly specific $\mathrm{MrgC}$ receptor agonist, as evidenced by the findings that BAM8-22 loses its bioaction following MrgC gene depletion (Guan et al., 2010) or receptor neutralization (Wang et al., 2016). We have observed that intrathecal administration of BAM8-22 prevents or inhibits morphine tolerance (Cai et al., 2007; Chen et al., 2010) and enhances morphine analgesia (Wang et al., 2013). The mechanisms underlying these effects involve inhibition of expression of pro-nociceptive mediators and signaling transduction pathways in neurons of spinal dorsal horn and/or DRG (Chen et al., 2010; Huang et al., 2014) and also the increase in coupling of $\mu$-opioid receptor (MOR) with inhibitory guanine nucleotide binding regulatory protein $\left(\mathrm{G}_{\mathrm{i}}\right.$ protein) (Wang et al., 2013). The present study investigated the effects of $\mathrm{MrgC}$ receptor on chronic morphine-induced spinal glial activation and its possible mechanisms.

\section{Materials and Methods}

Animals. Adult male Sprague-Dawley rats weighing 230-290 g were obtained from the Animal Center of Fujian Medical University (Fujian, China) and housed in a room maintained at $22^{\circ} \mathrm{C} \pm 0.5^{\circ} \mathrm{C}$ with an alternating 12-hour light-dark cycle (lights off at 0700 hours and on at 1900 hours). Animals had free access to food and water adding libitum. The study was conducted in accordance with the guidelines for investigations of experimental pain in conscious animals (Zimmermann, 1983) approved by the Ethics Committee on Animal Experimentation of Fujian Normal University. Following implantation of intrathecal catheter, rats were housed individually. Behavioral assessments were performed between 0830 and 1630 hours. Efforts were made to reduce the number of animals used.

Implantation of Intrathecal Catheter. Rats were implanted with indwelling catheters in the intrathecal space. Briefly, animals were injected with pentobarbital $(50 \mathrm{mg} / \mathrm{kg}$, i.p.; Shenggong, Shanghai, China). The dura mater overlying the atlanto-occipital membrane of rats was exposed and a small slit was cut in the membrane. A PE-10 tubing (Stoelting, Wood Dale, IL) was inserted into the intrathecal space with its tip being positioned at the level of lumbar enlargement (L4-L5). The catheter was flushed with saline $(10 \mu \mathrm{l})$ and closed. The rats then were allowed to recover for 1 week. The location of intrathecal catheter tip was confirmed by intrathecal injection of lidocaine ( $200 \mu \mathrm{g} / 10 \mu \mathrm{l}$; Shenggong), which caused a motor paralysis of the lower limbs. Vehicle (saline) or drug was administered intrathecally in a volume of $10 \mu \mathrm{l}$ under conscious condition.

Rats were made tolerant to the anesthetic action of morphine. Morphine hydrochloride ( $20 \mu \mathrm{g}$, i.t.; Northeast, Shenyang, Liaoning, China) was injected daily to rat for 6 days to induce tolerance to morphine. BAM8-22 (1 nmol, i.t.; Huadatianyuan, Shanghai, China) or saline was given on days 1, 3, and 5. Morphine or BAM8-22 was dissolved or diluted in saline.
Nociceptive Test. A behavior test evaluated response to heat stimulation in the tail and thereby the effect of drugs on nociceptive sensitivity in rats. Tail flick latency (TFL) was measured using a Tail Flick Meter (IITC Life Science Inc., Woodland Hills, CA). The animals were acclimatized to the environment (behavior testing) for 30-40 min for five days and also habituated for $15 \mathrm{~min}$ prior to testing to minimize individual variability of behavioral tests. A light source was directed at the underside of their tail and the latency to remove the tail was recorded. The baseline latency was approximately $2-3.2$ seconds and the cut-off latency was set to 10 seconds to avoid tissue injury. Three measurements of TFL were made at each time point and the averaged value was taken. The investigator was blind to the drug test conditions. Responses were expressed as percentage of maximum possible effect (\% MPE) of drug or vehicle was analyzed:

\section{$\% \mathrm{MPE}=([$ post-treatment TFL - pre-treatment TFL $] /$ [cut-off latency - pre-treatment TFL]) $\times 100 \%$}

Ganglion Explant Cultures. Rats were sacrificed through decapitation after being anesthetized with pentobarbital. All DRG (C2-L6) were collected under sterile technique. The ganglion explants were washed twice with Hanks' solution and transferred to Dulbecco's modified Eagle's medium (DMEM) supplemented with streptomycin/ penicillin and fetal bovine serum (10\%). The DRG explants were incubated in DMEM with a humidified $5 \% \mathrm{CO}_{2} / 95 \%$ air at $37^{\circ} \mathrm{C}$. Twenty-four hours later, DMEM medium was replaced and the cultures were exposed to saline or drugs for various time. The DRG explants were then harvested and stored at $-80^{\circ} \mathrm{C}$.

Immunohistochemistry. Animals were injected with pentobarbital $(55 \mathrm{mg} / \mathrm{kg}$ i.p.) and perfused transcardially with phosphatebuffered saline (PBS) $(0.01 \mathrm{M})$ followed by cold $4 \%$ paraformaldehyde in phosphate buffer $(0.1 \mathrm{M})$. Lumbar segments of the spinal cord (L4-L5) and DRG at L4-L6 were isolated and fixed for 8 hours in 4\% paraformaldehyde. Tissues were then cryoprotected with sucrose (30\% in PBS). Frozen sections (30 or $10 \mu \mathrm{m}$ ) were prepared from the spinal cord or DRG. The spinal cord or DRG sections were preincubated with PBS containing $\mathrm{H}_{2} \mathrm{O}_{2}(0.3 \%)$ and normal goat serum $(10 \%)$ for 1 hour. These sections were incubated with a rabbit anti-GFAP [G9269 (Serrano-Pozo et al., 2010; Piccin and Morshead, 2011), 1:2000; Sigma-Aldrich (Shanghai), Shanghai, China], mouse anti-OX-42 [sc53086 (Shi et al., 2016; Zhang et al., 2016), 1:1000; Santa Cruz Biotechnology, Shanghai, China], rabbit anti- P2X 4 [ab82329 (GarciaGuzman et al., 1997; Wu et al., 2011), 1:200; Abcam, Shanghai, China], or goat anti-fractalkine [sc-7225 (Huang et al., 2006; Tsubota et al., 2009), 1:50; Santa Cruz] antibody overnight at $4^{\circ} \mathrm{C}$. The sections were washed four times for 5 minutes each in PBS, followed by incubation with a Texas Red rhodamine-conjugated (1:1000; Abcam) or fluorescein isothiocyanate (FITC, 1:500 or 1:100; Abcam) secondary antibody (anti-rabbit, anti-mouse, or anti-goat) for 2 hours. After being thoroughly rinsed with PBS, the sections were dehydrated, air dried, and cover-slipped. The specificity of the antibodies for GFAP, OX-42, $\mathrm{P}_{2} \mathrm{X}_{4}$, and fractalkine was confirmed by the absence of staining of the tissue sections in experiments without the primary antibodies $(n=2$, each). The sections were examined under a fluorescence microscope

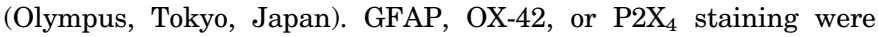
quantified as the number of pixels above a preset intensity threshold by image software (Image-Pro Plus 6.0, Silver Spring, MD), as described in previous study (Hong et al., 2010). Staining intensity of GFAP, OX-42, or P2X $\mathrm{X}_{4}$ was examined in the field of $100 \times 100 \mu \mathrm{m}$ from each of seven spinal dorsal horn sections per rat. An increase in pixel numbers was believed to indicate glial reactivity (Alkaitis et al., 2010; Horvath et al., 2010). Fractalkine-positive and negative DRG neurons were quantified using image software in an area of $200 \times 200 \mu \mathrm{m}$ from each of seven DRG sections per rat. The value of positive cells was expressed as a percentage of positive neurons plus negative neurons (total neurons). Experimenter was blinded to experimental conditions.

Western Blot. DRG explants were homogenized in cell lysis buffer (P0013D; Beyotime, Hangzhou, Zhejiang, China). Proteins in the 
samples were quantified by BCA protein assay kit (Pierce Chemical, Shanghai, China). Proteins (20 $\mu$ g each) were run on SDS gel $(7.5 \%)$ and transferred to polyvinylidene difluoride filters. The filters were blocked in PBS containing 7\% milk. Membranes were incubated with a primary antibody against IL- $1 \beta$ [ab9787 (Maddahi and Edvinsson, 2010; Gui et al., 2012), 1:500; Abcam], Toll-like receptor 4 [TLR4; sc-30002 (Gay and Keith, 1991; Medzhitov et al., 1997), 1:200; Santa Cruz], or $\beta$-actin (1:5000; Proteintech, Wuhan, Hubei, China). Blots were incubated with goat anti-rabbit IgG secondary antibody (1:10000; LI-COR Biosciences, Shanghai, China) or goat anti-mouse IgG secondary antibody (1:10000; LI-COR) or for 2 hours at room temperature. The band density of target proteins was measured with an imaging analysis software (Odyssey; LI-COR) and normalized against a loading control ( $\beta$-actin). Results are expressed as a fold change over the saline-treated control.

Quantitative Real-Time Polymerase Chain Reaction. RNA was extracted from the dorsal part of the spinal cord or DRG explants using the RNAprep Kit (Tiangen Bio-Tech, Beijing, China). DNA contamination was removed using deoxyribonuclease I. RNA concentrations were determined by measuring the absorbency at 260 and $280 \mathrm{~nm}$ with a UV spectrophotometer. Absorbency ratios of all samples were 1.8-2.0. One microgram of RNA was reversely transcripted into cDNA using Quantscript Reverse Transcription Kit (Tiangen).

The primer sequences of fractalkine and GAPDH were designed using software. The forward/reverse primers were:

\section{5'-GAGCCTCAGAGCACTGGAATT-3'/5'-GTGGACGCTTGAG- TAGATAGGG-3' for fractalkine and \\ 5'-GGCAAGTTCAACGGCACAG-3'/5' -CGCCAGTAGACTC- CACGACAT-3' for GAPDH.}

Twenty nanograms of cDNA from the same cDNA batch was subjected to real-time polymerase chain reaction (PCR) to amplify all genes in a total reaction volume of $20 \mu \mathrm{l}$, using SYBR Premix Ex Taq, ROX as internal reference dye (Takara Biotech, Dalian, China), and the forward and reverse primers. Reactions were conducted on a 7500 Fast Sequence Detection System (Applied Biosystems/Thermo Fisher Scientific, Waltham, MA). The thermal cycle conditions were: 30 seconds at $95^{\circ} \mathrm{C}, 40$ cycles (5 seconds) at $95^{\circ} \mathrm{C}$, and 30 seconds at $60^{\circ} \mathrm{C}$. All samples were tested in triplicate. A nontemplate reaction served as an negative control. Melting curve analysis of products as well as amplicon size verification on a $3 \%$ agarose gel confirmed the specificity of the PCR. The raw expression level of gene was calculated using the same external standard curve made with a mixture of cDNA samples. The expression of fractalkine gene was normalized to that of GAPDH gene control.

Statistical Analysis. All results are given as mean \pm S.E.M. Differences between groups were determined by one-way analysis of variance followed by Tukey's method. The criterion for statistical significance was $P<0.05$.

\section{Results}

Intermittent Treatment with BAM8-22 Prevents Development of Morphine Tolerance. As illustrated in Fig. 1, morphine-induced analgesia declined progressively following the 6-day morphine treatment ( $20 \mu \mathrm{g}$, i.t., daily). Antinociceptive tolerance was indicated by the low \%MPE on day 6 , which was significantly different from the value on day $1(P<0.05)$. However, when BAM8-22 $(1 \mathrm{nmol})$ was coadministered on days 1,3 , and 5 (defined as intermittent administration), morphine maintained proficiency to induce antinociception throughout the experiment. A one-nanomole dose of BAM8-22 was chosen on the basis of dose-response studies (Cai et al., 2007; Chen et al., 2010). Administration of saline on days $1-6$ or BAM8-22 (1 nmol) on days 1,3 , and

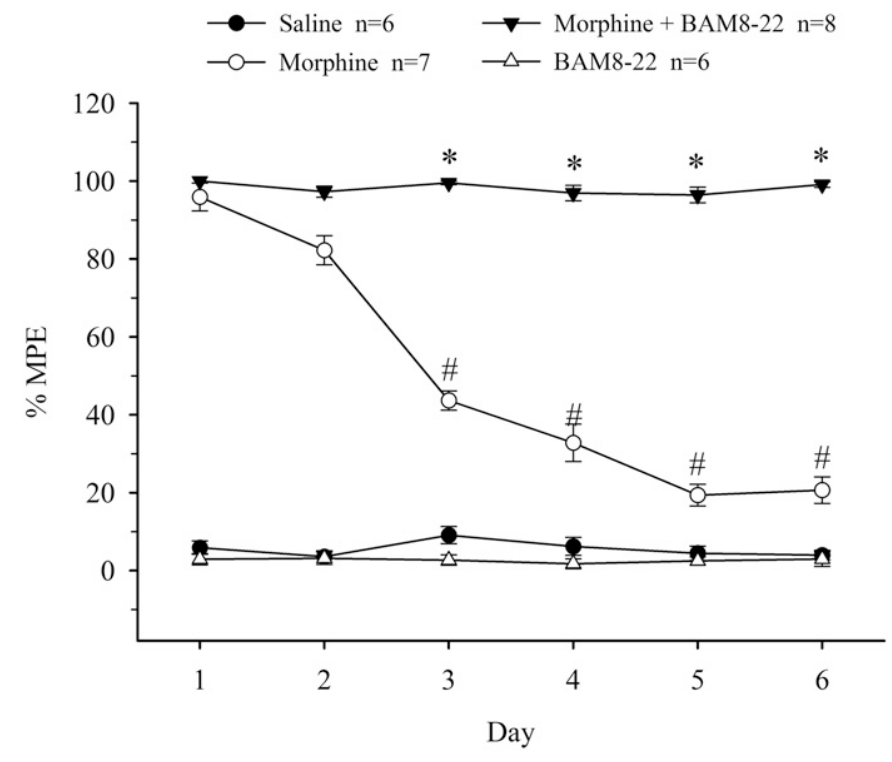

Fig. 1. Effect of BAM8-22 on the development of morphine tolerance. Morphine $(20 \mu \mathrm{g})$ or saline was administered intrathecally once per day for 6 days. BAM8-22 $(1 \mathrm{nmol})$ was given with morphine or alone on days 1,3 , and 5. The data are presented as mean \pm S.E.M. $* P<0.05$ compared with morphine group. ${ }^{\#} P<0.05$ compared with the value on day $1 . N=6-8$.

5 induced $1 \%-4 \%$ MPE. These values were not significantly different from the preadministration baselines $(P>0.05)$. These results are consistent with our previous observations (Cai et al., 2007; Chen et al., 2010) and validated the protocols that were used for immunocytochemical staining and Western blot assay in the present study.

Intermittent Treatment with BAM8-22 Inhibits Morphine-Induced Activation of Spinal Astrocytes and Microglia. Morphine $(20 \mu \mathrm{g})$, morphine plus BAM8-22 ( $1 \mathrm{nmol}$, intermittently), or saline were injected intrathecally for 6 days. The lumbar spinal cord was harvested on day 6 . Immunocytochemistry assay showed that chronic treatment with morphine remarkably changed the morphology of astrocytes, manifesting an enlargement of GFAP-staining cells and processes and an increase in fluorescence intensity $(P<0.05$, Fig. 2, B and E) compared with the saline treatment (Fig. 2, A, $\mathrm{D}$, and G). Following intermittent BAM8-22 administration, morphine-induced astrocytes were remarkably reduced (Fig. 2, C and F) and fluorescence intensity of GFAP in this group was not significantly different from the saline group $(P>0.05$, Fig. 2G). GFAP-stained fluorescence intensity in the morphine/ BAM8-22 group was significantly lower than the morphine group $(P<0.05$, Fig. 2G).

Following chronic morphine treatment, microglia showed typical amoeboid change. OX-42 immunoreactivity was significantly increased $(P<0.05$, Fig. $3, \mathrm{~B}$ and D) compared with the saline treatment (Fig. 3, A and D). Intermittent administration of BAM8-22 remarkably attenuated the morphological changes of microglia. The OX-42-stained fluorescence intensity was significantly lower than the morphine group $(P<$ 0.05 , Fig. $3, \mathrm{C}$ and $\mathrm{D})$. There was no significant difference between the morphine/BAM8-22 and saline groups for the expression of OX-42 $(P>0.05$, Fig. 3D).

Intermittent Treatment with BAM8-22 Attenuates Morphine-Induced Expression of $\mathrm{P}_{2} \mathrm{X}_{4}$ and $\mathrm{IL-1} \beta$ in Spinal Cord. Morphine $(20 \mu \mathrm{g})$, morphine plus BAM8-22 

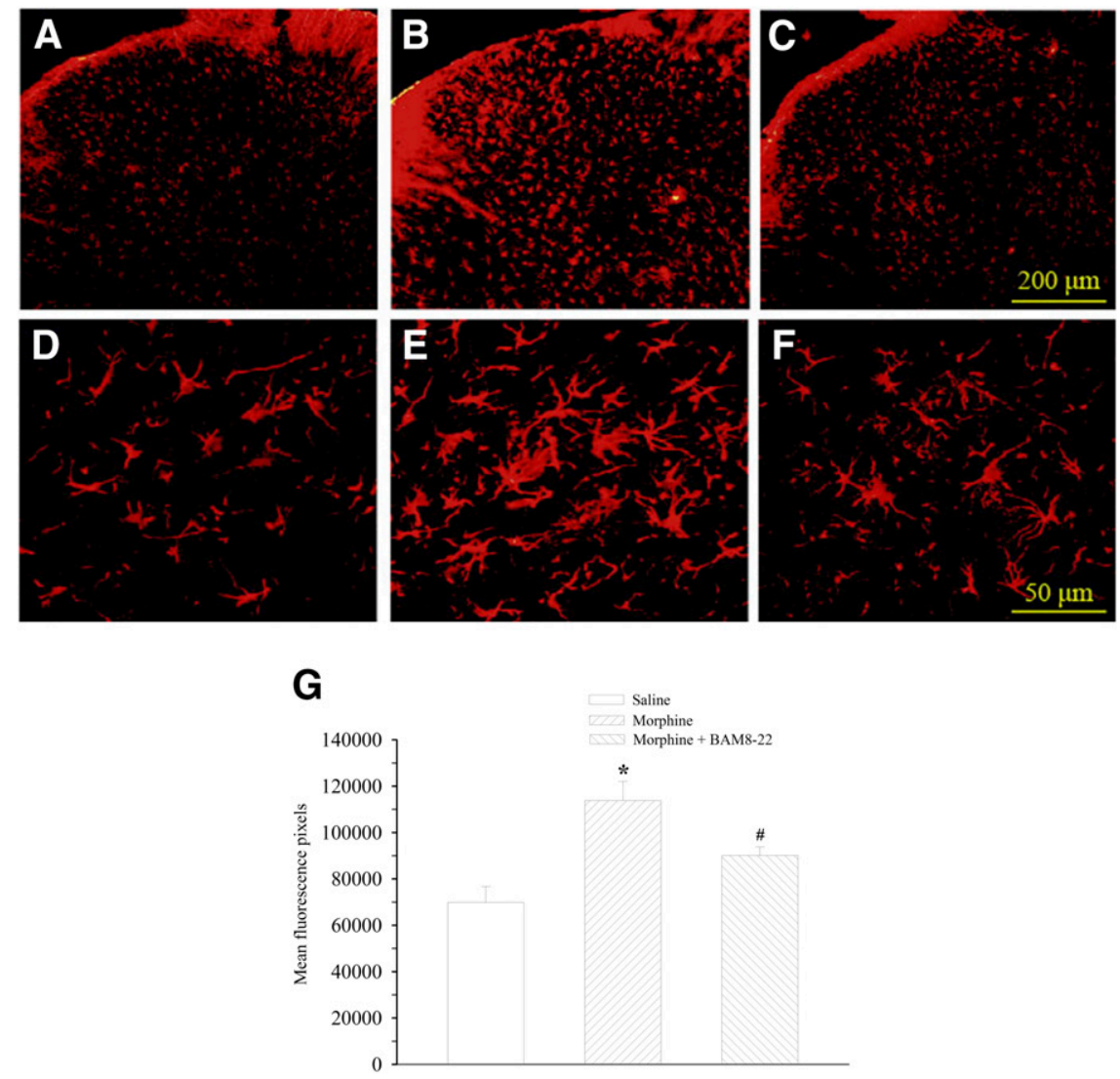

Fig. 2. GFAP immunofluorescence staining in the spinal dorsal horn. Saline (A and D), morphine $(20 \mu \mathrm{g})(\mathrm{B}$ and E), or morphine + BAM8-22 $(1 \mathrm{nmol}$, on days 1,3 , and 5 ) ( $\mathrm{C}$ and $\mathrm{F}$ ) were given intrathecally once per day for 6 days. The lumbar spinal cord was harvested on day 6 and processed with immunofluorescence staining. The GFAP staining intensity was quantified as pixels $(\mathrm{G}) . * P<0.05$ compared with saline group. ${ }^{\sharp P}<0.05$ compared with morphine group. Scale bar, $200 \mu \mathrm{m}(\mathrm{A}-\mathrm{C})$ or $50 \mu \mathrm{m}(\mathrm{D}-\mathrm{F}) . N=6$.

( $1 \mathrm{nmol}$, intermittently), or saline were injected intrathecally for 6 days. The lumbar spinal cord or the dorsal half of the lumbar spinal cord was harvested on day 6 and assayed by immunocytochemistry staining or Western blot. Chronic morphine delivery significantly increased the protein expression of $\mathrm{P}_{2} \mathrm{X}_{4}$ receptor on day 6 (Fig. $4 \mathrm{~B}$ ) compared with the group receiving saline injection $(P<0.05$, Fig. $4 \mathrm{~A})$. Intermittent administration of BAM8-22 reduced morphine-induced
P2X $\mathrm{X}_{4}$ immunofluorescence to a level that was significantly lower than the morphine group ( $P<0.05$, Fig. $4, \mathrm{C}$ and $\mathrm{D})$ but still higher than the saline group $(P<0.05)$.

Chronic morphine exposure significantly increased the expression of IL- $1 \beta$ protein in the spinal dorsal horn on day 6 (Fig. 5) compared with the saline treatment $(P<0.05)$. However, morphine failed to change the level of IL- $1 \beta$ expression following the intermittent cotreatment with
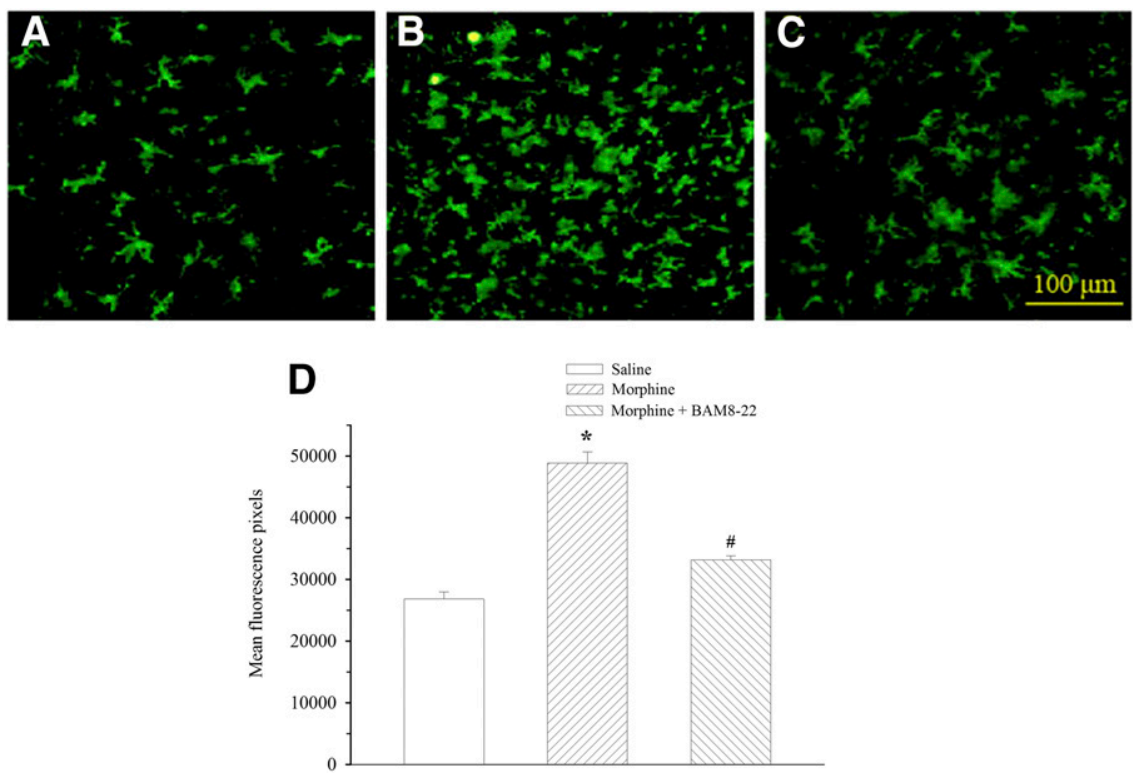

Fig. 3. OX-42 immunofluorescence staining in the spinal dorsal horn. Saline (A), morphine $(20 \mu \mathrm{g})(\mathrm{B})$, or morphine + BAM8-22 (1 nmol, on days 1,3 , and 5) (C) were given intrathecally once per day for 6 days. The lumbar spinal cord was harvested on day 6 and processed with immunofluorescence staining. The OX-42 staining intensity was quantified as pixels (D). ${ }^{*} P<0.05$ compared with saline group. ${ }^{\#} P<0.05$ compared with morphine group. Scale bar, $100 \mu \mathrm{m}$. $N=6$. 

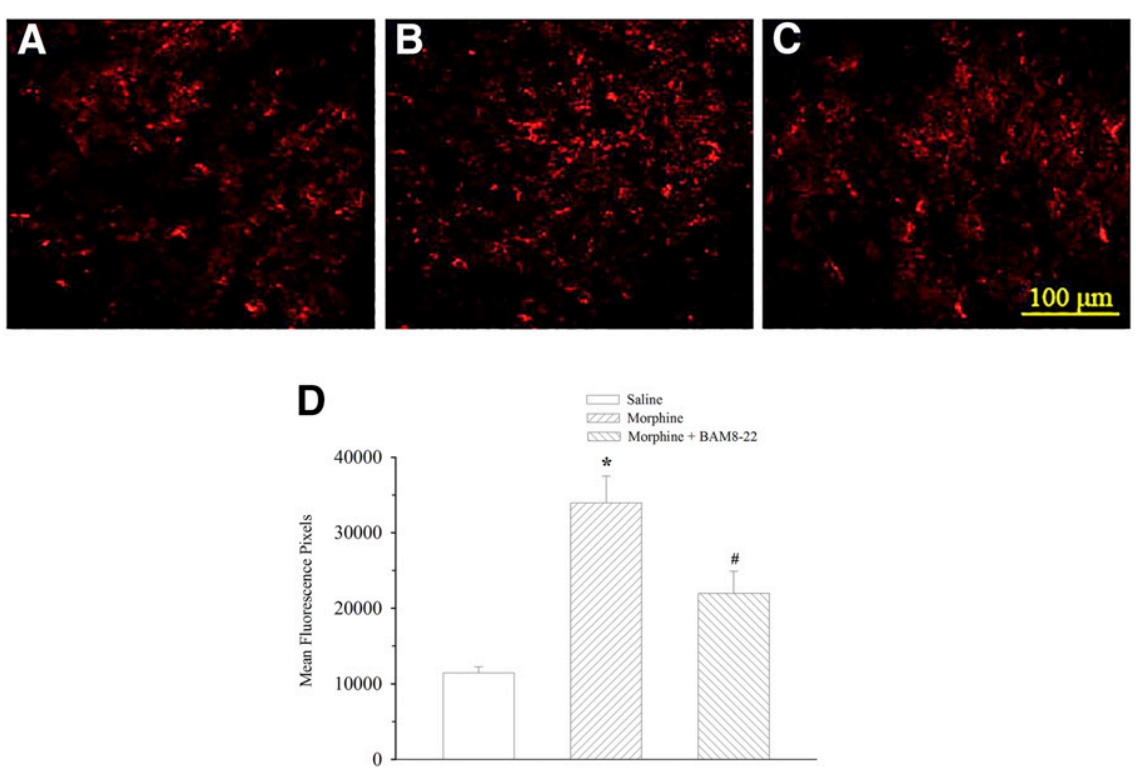

BAM8-22. Statistical examination indicated that IL-1 $\beta$ expression in the morphine/BAM8-22 group was not significantly different from the saline group $(P>0.05$, Fig. 5$)$ and significantly lower than the morphine group $(P<0.05$, Fig. 5$)$.

Intermittent Treatment with BAM8-22 Reduces Morphine-Induced Expression of TLR $_{4}$ and Fractalkine in DRG In Vivo. The experimental protocol was identical to above studies. DRG at L4-L6 were harvested on day 6 . Figure 6 shows that the chronic exposure of morphine caused an increase in the level of $\mathrm{TLR}_{4}$ protein, which was significantly higher than that in the saline group $(P<0.05)$. However, morphine induced less $\mathrm{TLR}_{4}$ expression following the intermittent coadministration of BAM8-22, as the level of $\mathrm{TLR}_{4}$ was greatly lower than in the morphine group $(P<0.05)$ but not significantly different from the saline group $(P<0.05)$.

Fractalkine immunofluorescence was found in medium- and small-sized neurons in DRG of saline-treated rats (Fig. 7A). Chronic morphine exposure remarkably increased the expression of fractalkine in both sizes of neurons $(P<0.05$, Fig. $7, \mathrm{~B}$ and D). Following intermittent treatment with BAM8-22, the numbers of morphine-induced fractalkine neurons in medium and small subpopulations were greatly reduced. The reduction was statistically significant compared with the morphine group ( $P<0.05$, Fig. $7, \mathrm{C}$ and $\mathrm{D})$. There was no significant difference between the morphine/BAM8-22 and saline groups for the expression of fractalkine in medium and small subpopulations of neurons $(P>0.05$, Fig. 7D).

BAM8-22 Reduces Chronic Morphine-Induced Expression of Fractalkine in DRG Ex Vivo. DRG explant cultures were exposed to morphine $(3.3 \mu \mathrm{M})$ or saline for 5 days. On day 5, BAM8-22 (10 $\mathrm{nM})$ or saline were applied to the cultures for 60 minutes and then the DRG were harvested. Total mRNA from cultured DRG was isolated and the levels of fractalkine mRNA were evaluated. GAPDH mRNA was assayed as an internal standard. Fractalkine mRNA was detected in saline-treated DRG. The 5-day treatment with morphine greatly increased the level of fractalkine mRNA ( $P<0.05$ vs. saline control, Fig. 8). However, the morphine treatment failed to increase fractalkine mRNA following the application of BAM8-22. Statistical analysis indicates that the level of fractalkine mRNA in the morphine/BAM8-22 group was remarkably lower than the morphine group $(P<0.05)$ but not significantly different from the saline group $(P>0.05)$.

\section{Discussion}

The current study demonstrated that intermittent treatment with BAM8-22, a specific MrgC receptor agonist, did not change tail flick latency, confirming that activation of $\mathrm{MrgC}$ receptor does not impact pain sensitivity (Cai et al., 2007;

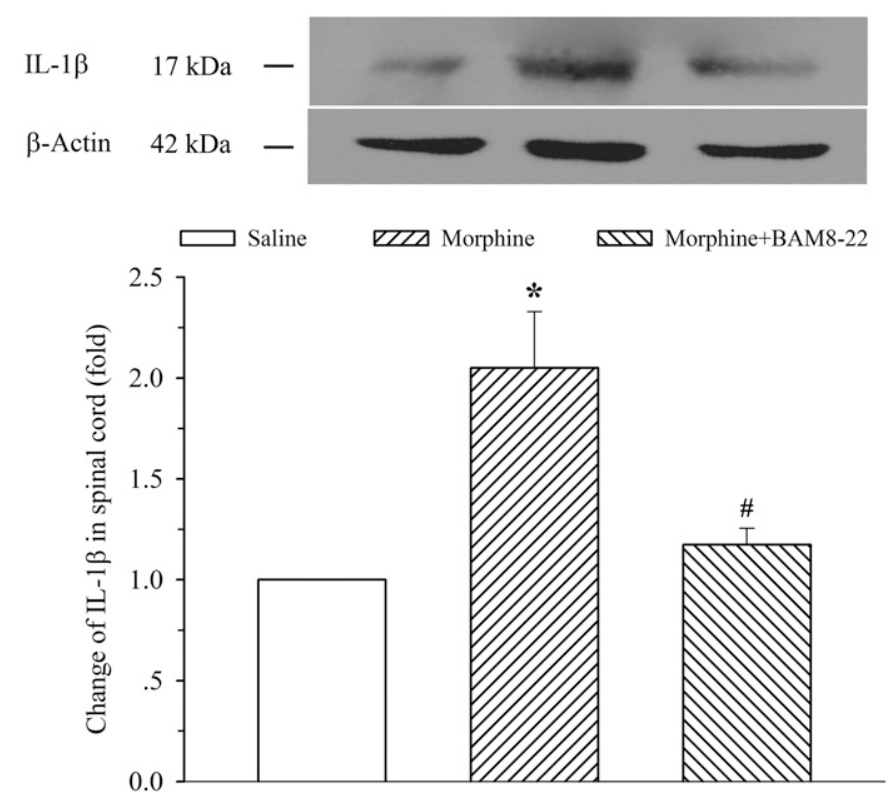

Fig. 5. Expression of IL-1 $\beta$ in the spinal dorsal horn. Saline, morphine $(20 \mu \mathrm{g})$, or morphine + BAM8-22 $(1 \mathrm{nmol}$, on days 1,3 , and 5$)$ were given intrathecally once per day for 6 days. The lumbar spinal cord was harvested on day 6 and processed with Western blot assay. Histograms indicate the percentage of density of IL- $1 \beta$ protein immunobands over $\beta$-actin bands. Data for individual IL- $1 \beta$ band were corrected by normalizing it to corresponding loading control. $* P<0.05$ compared with control, ${ }^{\#} P<0.05$ compared with morphine group. $N=5$ each. 

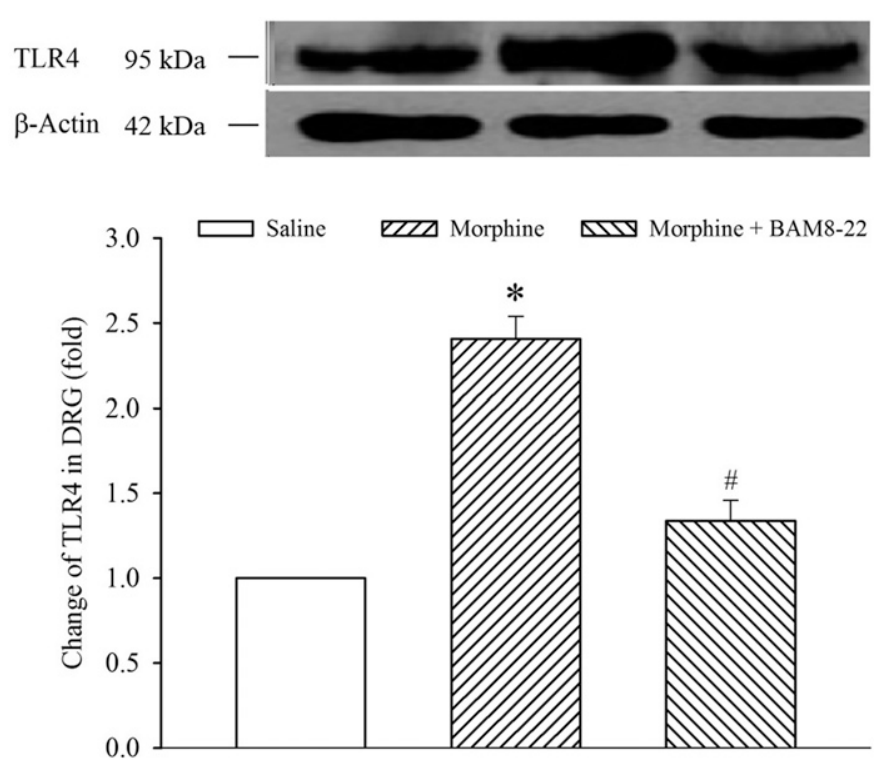

Fig. 6. Expression of $\mathrm{TLR}_{4}$ in DRG. Saline, morphine $(20 \mu \mathrm{g})$, or morphine $(20 \mu \mathrm{g})+$ BAM8-22 (1 nmol, on days 1,3 , and 5) were given intrathecally once per day for 6 days. DRG at L4-6 were harvested on day 6 and processed with Western blot assay. Histograms indicate the percentage of density of $\mathrm{TLR}_{4}$ immunobands over $\beta$-actin bands. Data for individual $\mathrm{TLR}_{4}$ bands were corrected by normalizing it to corresponding loading control. ${ }^{*} P<0.05$ compared with control, ${ }^{\#} P<0.05$ compared with morphine group. $N=5$ each.

Chen et al., 2010; Guan et al., 2010). However, similar treatment with BAM8-22 prevented the development of morphine tolerance. This result accorded with our previous observations (Cai et al., 2007; Chen et al., 2010) and validated the experimental protocols that were used to investigate the molecular mechanisms underlying the effects of $\mathrm{MrgC}$ receptor activation on morphine tolerance in this study.

We first determined the effects of $\mathrm{MrgC}$ receptor activation on the morphine-induced morphologic changes of astrocytes and microglia in the spinal cord, since glial activation plays an important role in the development of morphine tolerance
(Watkins et al., 2005). Our study showed that following chronic morphine exposure, glial cells became hypertrophic and GFAP/OX-42 immunoreactivity in the spinal dorsal horn was remarkably increased. These changes were in agreement with those reported in previous studies (Raghavendra et al., 2002; Tawfik et al., 2005). Interestingly, the morphologic changes in both astrocytes and microglia were attenuated or inhibited by the intermittent administration of the $\mathrm{MrgC}$ receptor agonist BAM8-22. It may be argued that $\mathrm{MrgC}$ receptor only modulated microglial activation and the inhibition of astrocytes was the consequence of the microglial deactivation. The basis of this argument was reports that microglia are activated first and in turn lead to the activation of astrocytes in pathologic pain (Tanga et al., 2004) and chronic morphine exposure (Cui et al., 2008). However, there is evidence showing that the inhibition of astrocytes can prevent the development of neuropathic pain (Zhuang et al., 2006) and morphine tolerance (Song and Zhao, 2001). In particular, a study using primary astrocyte cultures has demonstrated that morphine treatment increases the synthesis and secretion of proteins in astrocytes (Rönnbäck and Hansson, 1988). Therefore, the current study proposes that inhibition of both astrocyte and microglia in the spinal cord underlies the modulation of morphine tolerance by MrgC receptor.

Activation/inhibition of behavioral or signaling pathways of pain can be dissociated by changes in glial marker expression in the spinal cord (Zhuang et al., 2006; Horvath et al., 2010) or DRG (Fu et al., 2010). An increase in glial marker expression may not be correlated necessarily with pain hypersensitivity (Ulmann et al., 2008; Beggs et al., 2012). Therefore, we further studied the effect of $\mathrm{MrgC}$ receptor on the functional changes in activated glial cells. $\mathrm{P}_{2} \mathrm{X}_{4}$ receptor and IL- $1 \beta$ are upregulated in glial cells as functional changes in activated glia following chronic morphine exposure (Hutchinson et al., 2011). $\mathrm{P} 2 \mathrm{X}_{4}$ receptor is expressed in microglia (Tsuda et al., 2003; Ulmann et al., 2008). $\mathrm{P}_{2} \mathrm{X}_{4}$ receptor signaling is involved in the pathogenesis of neuropathic pain (Beggs et al., 2012; Tsuda, 2017) and morphine tolerance (Horvath et al., 2010).
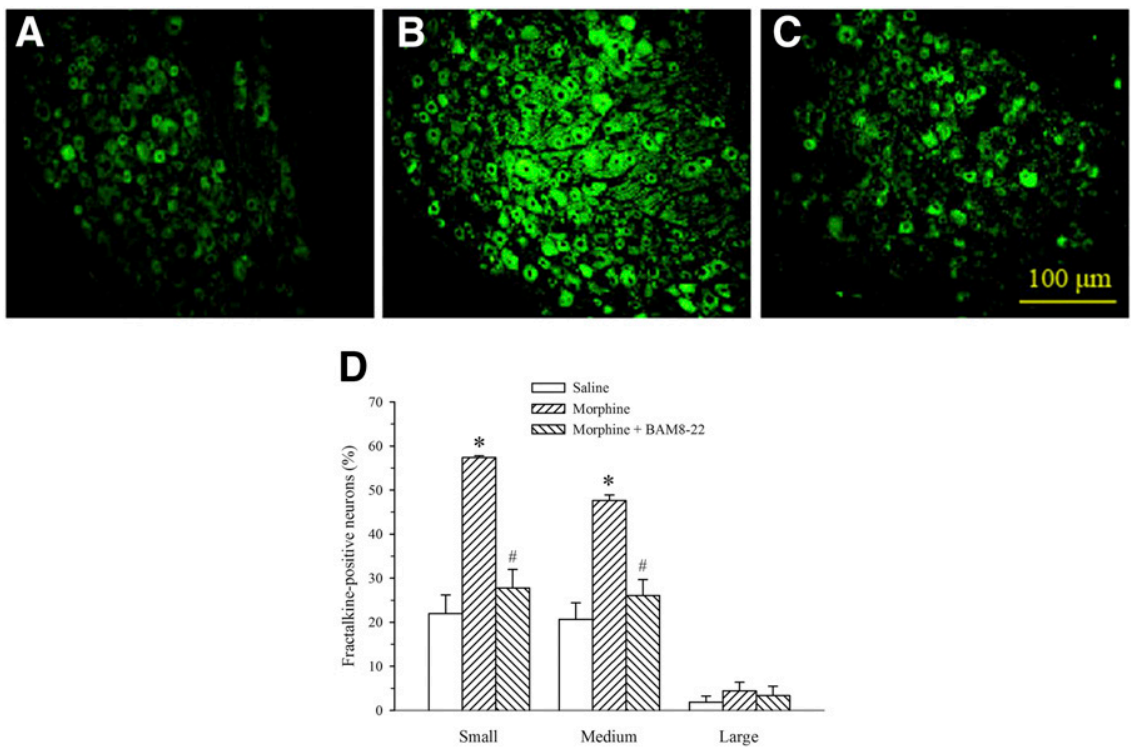

Fig. 7. Expression of fractalkine in DRG in vivo. Saline (A), morphine $(20 \mu \mathrm{g})(\mathrm{B})$, or morphine $(20 \mu \mathrm{g})$ + BAM8-22 (1 nmol, on days 1,3 , and 5) (C) were given intrathecally once per day for 6 days. DRG at L4-L6 were harvested on day 6 and processed with immunofluorescence staining. Histograms (mean \pm S.E.M.) (D) show the proportion of fractalkinepositive neurons over the total correspondingly sized subpopulations of DRG. $* P<0.05$ compared with saline group, ${ }^{\#} P<0.05$ compared with morphine group. Scale bar, $100 \mu \mathrm{m} . N=5$ each. 


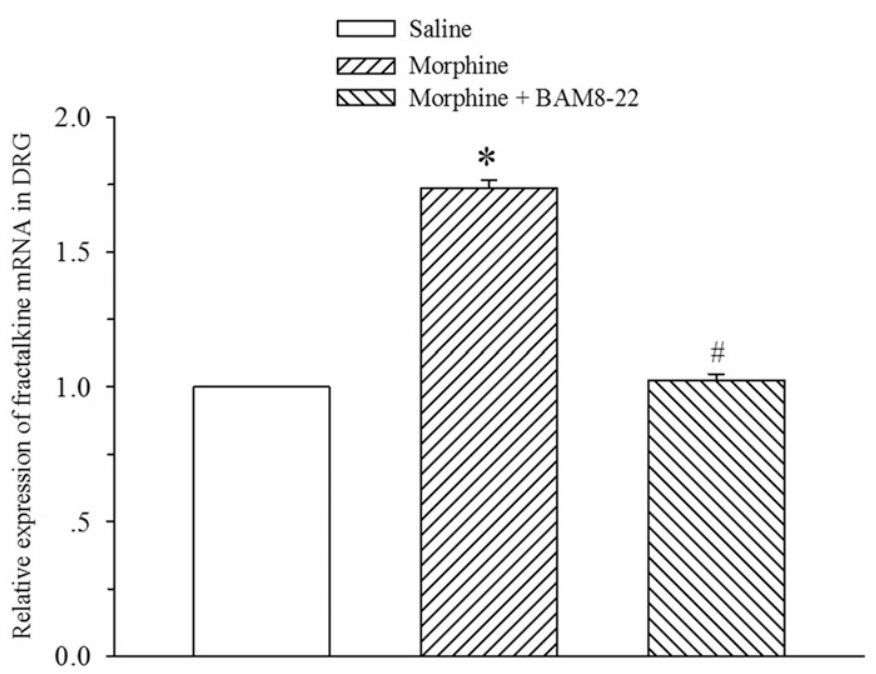

Fig. 8. Expression of fractalkine mRNA in DRG ex vivo. DRG explants were cocultured with saline or morphine $(3.3 \mu \mathrm{M})$ for 5 days. On day 5 , BAM8-22 $(10 \mathrm{nM})$ or saline was applied to the cultures for 60 minutes and then the DRG were harvested. mRNA levels of fractalkine mRNA were assayed. ${ }^{*} P<0.05$ compared with saline group, ${ }^{\#} P<0.05$ compared with morphine group. $N=4$ each.

Chronic morphine use enhances $\mathrm{P}_{4} \mathrm{X}_{4}$ receptor expression in microglial cultures (Horvath and DeLeo, 2009) and the spinal dorsal horn in vivo (Horvath et al., 2010). In particular, knocking down $\mathrm{P}_{2} \mathrm{X}_{4}$ receptor by intrathecal administration of antisense oligonucleotide attenuated the development of morphine tolerance as well as morphine-induced increase of Iba1 (microglial marker) and GFAP expressions (Horvath et al., 2010). IL- $1 \beta$ is mainly sourced from activated astrocytes (Palma et al., 1997) and microglia (Tikka et al., 2001). This cytokine can sensitize spinal sensory neurons (Reeve et al., 2000; Kawasaki et al., 2008) as it enhances neuronal $N$-methyl-D-aspartic acid conductance (Viviani et al., 2003), inhibits glutamate transporter-1 (GLT-1) and glutamateaspartate transporter (GLAST) (Prow and Irani, 2008) and facilitates the release of other nociceptive molecules, including substance P (Inoue et al., 1999) and prostaglandin (Samad et al., 2001). IL-1 $\beta$ is elevated in morphine-tolerant animals (Johnston et al., 2004; Raghavendra et al., 2004). Blockade of IL-1 $\beta$ receptor signaling prevents the induction of morphine tolerance (Shavit et al., 2005) and also reverses the analgesic tolerance to morphine (Johnston et al., 2004; Shavit et al., 2005). As in previous studies, our data showed that chronic morphine exposure induced an increase in expression of $\mathrm{P}_{2} \mathrm{X}_{4}$ receptor and IL-1 $\beta$. Importantly, the increase in these two molecules was attenuated or inhibited following the intermittent $\mathrm{MrgC}$ receptor activation. These results suggest that the attenuation of $\mathrm{P}_{2} \mathrm{X}_{4}$ and IL- $1 \beta$ expressions by MrgC receptor can result in the inhibition of morphine tolerance.

The dorsal root ganglion is one of key sites of nociceptive processing (Millan, 1999) and an active organ in the induction of chronic pain (Krames, 2014). It also plays an important role in morphine tolerance by multiple mechanisms, including the increase in expression of nociceptive mediators (Liu and Prather, 2001; Walwyn et al., 2007; Hong et al., 2010). MrgC receptor is uniquely distributed in DRG neurons (Dong et al., 2001) and the central terminals of primary afferents (Huang et al., 2014). Chronic morphine exposure upregulates MrgC receptor expression in superficial laminae of the spinal cord and MrgC mRNA level in DRG (Huang et al., 2014) likewise to that observed in neuropathic pain (He et al., 2014a). Therefore, effects of MrgC receptor activation on the expression of $\mathrm{TLR}_{4}$ and fractalkine in DRG were determined. Chronic treatment with morphine upregulates expression of $\mathrm{TLR}_{4}$ (Hutchinson et al., 2008), leading to the induction of proinflammation (Wang et al., 2012), whereas the blockade of TLR $_{4}$ activity attenuates the development of morphine tolerance (Hutchinson et al., 2010; Liu et al., 2011). TLR $_{4}$ is present in sensory neurons, but not in non-neuronal cells, in the DRG (Due et al., 2012). Activation of $\mathrm{TLR}_{4}$ induces hyperexcitability of DRG neurons by increasing sodium current (Due et al., 2012, 2014). Fractalkine, also named CX3CL1, is a chemokine and is only expressed in neurons, not in glial cells, in DRG (Verge et al., 2004; Milligan et al., 2008). Because its only receptor, CX3CR, is expressed in microglia (Milligan et al., 2008) and satellite cells (Souza et al., 2013), fractalkine is believed to play a critical role in neuron-to-glia communication (Milligan et al., 2008; Clark et al., 2009). Indeed, fractalkine signaling in DRG has been demonstrated to be involved in nociceptive transmission in inflammatory pain (Souza et al., 2013; Zhu et al., 2013) and neuropathic pain (Galloway and Chattopadhyay, 2013). Injection of fractalkine into DRG can produce pain hypersensitivity, which is attributed to the production and release of tumor necrosis factor $\alpha$, IL- $1 \beta$, and prostaglandin E2 from satellite cells (Souza et al., 2013). However, whether TLR4 and fractalkine signaling in DRG contribute to the development of morphine tolerance has not been known. We demonstrated that chronic exposure to morphine increased the expression of $\mathrm{TLR}_{4}$ and fractalkine in DRG in vivo and/or ex vivo. These results can be interpreted as the involvement of $\mathrm{TLR}_{4}$ and fractalkine in morphine tolerance, since the increase in $\mathrm{TLR}_{4}$ (Due et al., 2012, 2014) and fractalkine (Souza et al., 2013) signaling can induce hyperexcitability of DRG neurons. On the other hand, treatment with BAM8-22 abolished increases in $\mathrm{TLR}_{4}$ and fractalkine induced by chronic morphine in and/or ex vivo. As an increase in nociceptive mediators in DRG is one of the major pathologic alterations in morphine tolerance and $\mathrm{MrgC}$ receptor is expressed in DRG neurons, modulation of the expression of $\mathrm{TLR}_{4}$ and fractalkine in DRG by MrgC receptor activation may be ascribed to the inhibition of glial activation and expression of $\mathrm{P}_{2} \mathrm{X}_{4}$ and IL- $1 \beta$ in the spinal cord.

Chronic morphine administration results in a reduction or loss of morphine-induced analgesia and pain hypersensitivity, making pain management difficult. Therefore, the prevention of opioid tolerance is critical to pain management in the clinic. The current study showed that the activation of $\mathrm{MrgC}$ receptor attenuated morphine-activated morphologic changes in astrocytes and microglia in the spinal cord. MrgC receptor also inhibited the expression of $\mathrm{P}_{2} \mathrm{X}_{4}$ receptor and IL-1 $\beta$, the functional changes of activated glia. Furthermore, MrgC receptor activation inhibited the morphine-induced expression of $\mathrm{TLR}_{4}$ and fractalkine in DRG. Administration of BAM8-22 alone has been shown to not change the expression of protein kinase $\mathrm{C} \gamma$ (Chen et al., 2010; Wang et al., 2015), phosphorylated extracellular signal-regulated protein kinase, and $G$ proteins $\left(G_{i}, G_{s}\right.$, and $\left.G_{q}\right)$ in the spinal dorsal horn and/or DRG (Wang et al., 2015). However, we cannot exclude the possibility that BAM8-22 could lower GFAP, OX-42, $\mathrm{P}_{2}$,

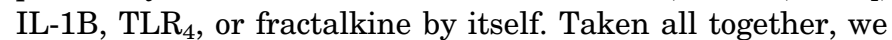
suggest that the inhibition of $\mathrm{TLR}_{4}$ and fractalkine in DRG 
may underlie the effects of $\mathrm{MrgC}$ on spinal glial activation, leading to the inhibition of morphine tolerance. Studies to further reveal mechanisms of MrgC-induced inhibition of $\mathrm{TLR}_{4}$ and fractalkine are warranted.

\section{Authorship Contributions}

Participated in research design: Huang, Hong.

Conducted experiments: Zhang, Wang, Lu, Li, Lin.

Performed data analysis: Zhang, Wang, Li, Lin.

Wrote or contributed to the writing of the manuscript: Hong.

\section{References}

Alkaitis MS, Solorzano C, Landry RP, Piomelli D, DeLeo JA, and Romero-Sandoval EA (2010) Evidence for a role of endocannabinoids, astrocytes and p38 phosphorylation in the resolution of postoperative pain. PLoS One 5:e10891.

Beggs S, Trang T, and Salter MW (2012) P2X4R+ microglia drive neuropathic pain. Nat Neurosci 15:1068-1073.

Cai Q, Jiang J, Chen T, and Hong Y (2007) Sensory neuron-specific receptor agonist BAM8-22 inhibits the development and expression of tolerance to morphine in rats. Behav Brain Res 178:154-159.

Chen P, Wang D, Li M, Zhang Y, Quirion R, and Hong Y (2010) Modulation of sensory neuron-specific receptors in the development of morphine tolerance and its neurochemical mechanisms. J Neurosci Res 88:2952-2963.

Choi SS and Lahn BT (2003) Adaptive evolution of MRG, a neuron-specific gene family implicated in nociception. Genome Res 13:2252-2259.

Clark AK, Yip PK, and Malcangio M (2009) The liberation of fractalkine in the dorsal horn requires microglial cathepsin S. J Neurosci 29:6945-6954.

Cui Y, Liao XX, Liu W, Guo RX, Wu ZZ, Zhao CM, Chen PX, and Feng JQ (2008) A novel role of minocycline: attenuating morphine antinociceptive tolerance by in hibition of p38 MAPK in the activated spinal microglia. Brain Behav Immun 22 $114-123$.

Davis TP, Hoyer GL, Davis P, and Burks TF (1990) Proenkephalin A-derived peptide $\mathrm{E}$ and its fragments alter opioid contractility in the small intestine. Eur J Pharmacol 191:253-261.

Dong X, Han S, Zylka MJ, Simon MI, and Anderson DJ (2001) A diverse family of GPCRs expressed in specific subsets of nociceptive sensory neurons. Cell 106 619-632.

Due MR, Piekarz AD, Wilson N, Feldman P, Ripsch MS, Chavez S, Yin H, Khanna R, and White FA (2012) Neuroexcitatory effects of morphine-3-glucuronide are dependent on Toll-like receptor 4 signaling. J Neuroinflammation 9:200.

Due MR, Yang XF, Allette YM, Randolph AL, Ripsch MS, Wilson SM, Dustrude ET, Khanna R, and White FA (2014) Carbamazepine potentiates the effectiveness of morphine in a rodent model of neuropathic pain. PLoS One 9:e107399.

Fu ES, Zhang YP, Sagen J, Candiotti KA, Morton PD, Liebl DJ, Bethea JR, and Brambilla R (2010) Transgenic inhibition of glial NF-kappa B reduces pain behavior and inflammation after peripheral nerve injury. Pain 148:509-518.

Galloway C and Chattopadhyay M (2013) RETRACTED: increases in inflammatory mediators in DRG implicate in the pathogenesis of painful neuropathy in type 2 diabetes. Cytokine 63:1-5.

Garcia-Guzman M, Soto F, Gomez-Hernandez JM, Lund PE, and Stühmer W (1997) Characterization of recombinant human P2X4 receptor reveals pharmacological differences to the rat homologue. Mol Pharmacol 51:109-118.

Gay NJ and Keith FJ (1991) Drosophila Toll and IL-1 receptor. Nature 351:355-356.

Guan Y, Liu Q, Tang Z, Raja SN, Anderson DJ, and Dong X (2010) Mas-related G-protein-coupled receptors inhibit pathological pain in mice. Proc Natl Acad Sci USA 107:15933-15938.

Gui J, Xiong F, Li J, and Huang G (2012) Effects of acupuncture on Th1, th2 cytokines in rats of implantation failure. Evid Based Complement Alternat Med 2012: 893023.

Haydon PG (2001) GLIA: listening and talking to the synapse. Nat Rev Neurosci 2: 185-193.

He SQ, Han L, Li Z, Xu Q, Tiwari V, Yang F, Guan X, Wang Y, Raja SN, Dong X, et al. (2014a) Temporal changes in MrgC expression after spinal nerve injury. Neuroscience 261:43-51.

He SQ, Li Z, Chu YX, Han L, Xu Q, Li M, Yang F, Liu Q, Tang Z, Wang Y, et al (2014b) MrgC agonism at central terminals of primary sensory neurons inhibits neuropathic pain. Pain 155:534-544.

Hong Y, Wang D, Chabot JG, Ma W, Chen P, and Quirion R (2010) A role for protein kinase C-dependent upregulation of adrenomedullin in the development of morphine tolerance in male rats. $J$ Neurosci 30:12508-12516.

Horvath RJ and DeLeo JA (2009) Morphine enhances microglial migration through modulation of P2X4 receptor signaling. J Neurosci 29:998-1005.

Horvath RJ, Romero-Sandoval EA, and De Leo JA (2010) Inhibition of microglial P2X4 receptors attenuates morphine tolerance, Iba1, GFAP and mu opioid receptor protein expression while enhancing perivascular microglial ED2. Pain 150: 401-413.

Huang D, Shi FD, Jung S, Pien GC, Wang J, Salazar-Mather TP, He TT, Weaver JT, Ljunggren HG, Biron CA, et al. (2006) The neuronal chemokine CX3CL1/ fractalkine selectively recruits $\mathrm{NK}$ cells that modify experimental autoimmune encephalomyelitis within the central nervous system. FASEB $J$ 20:896-905.

Huang H, Li Q, Hong YG, and Wang DM (2014) MrgC receptor activation reverses chronic morphine-evoked alterations of glutamate transporters and nNOS in rats. Sheng Li Xue Bao 66:449-456.

Hutchinson MR, Coats BD, Lewis SS, Zhang Y, Sprunger DB, Rezvani N, Baker EM Jekich BM, Wieseler JL, Somogyi AA, et al. (2008) Proinflammatory cytokines oppose opioid-induced acute and chronic analgesia. Brain Behav Immun 22: $1178-1189$

Hutchinson MR, Shavit Y, Grace PM, Rice KC, Maier SF, and Watkins LR (2011) Exploring the neuroimmunopharmacology of opioids: an integrative review of mechanisms of central immune signaling and their implications for opioid analgesia. Pharmacol Rev 63:772-810.

Hutchinson MR, Zhang Y, Shridhar M, Evans JH, Buchanan MM, Zhao TX, Slivka PF, Coats BD, Rezvani N, Wieseler J, et al. (2010) Evidence that opioids may have toll-like receptor 4 and MD-2 effects. Brain Behav Immun 24:83-95.

Inoue A, Ikoma K, Morioka N, Kumagai K, Hashimoto T, Hide I, and Nakata Y (1999) Interleukin-1beta induces substance $\mathrm{P}$ release from primary afferent neurons through the cyclooxygenase-2 system. $J$ Neurochem 73:2206-2213.

Jiang J, Wang D, Zhou X, Huo Y, Chen T, Hu F, Quirion R, and Hong Y (2013) Effect of Mas-related gene (Mrg) receptors on hyperalgesia in rats with CFA-induced inflammation via direct and indirect mechanisms. Br J Pharmacol 170:1027-1040.

Johnston IN, Milligan ED, Wieseler-Frank J, Frank MG, Zapata V, Campisi J, Langer S, Martin D, Green P, Fleshner M, et al. (2004) A role for proinflammatory cytokines and fractalkine in analgesia, tolerance, and subsequent pain facilitation induced by chronic intrathecal morphine. J Neurosci 24:7353-7365.

Kawasaki Y, Zhang L, Cheng JK, and Ji RR (2008) Cytokine mechanisms of central sensitization: distinct and overlapping role of interleukin-1beta, interleukin-6, and tumor necrosis factor-alpha in regulating synaptic and neuronal activity in the superficial spinal cord. $J$ Neurosci 28:5189-5194.

Krames ES (2014) The role of the dorsal root ganglion in the development of neuropathic pain Pain Med 15:1669-1685.

Lembo PM, Grazzini E, Groblewski T, O’Donnell D, Roy MO, Zhang J, Hoffert C, Cao J, Schmidt R, Pelletier M, et al. (2002) Proenkephalin A gene products activate a new family of sensory neuron--specific GPCRs. Nat Neurosci 5:201-209.

Liu JG and Prather PL (2001) Chronic exposure to mu-opioid agonists produces constitutive activation of mu-opioid receptors in direct proportion to the efficacy of the agonist used for pretreatment. Mol Pharmacol 60:53-62.

Liu L, Coller JK, Watkins LR, Somogyi AA, and Hutchinson MR (2011) Naloxoneprecipitated morphine withdrawal behavior and brain IL-1 $\beta$ expression: comparison of different mouse strains. Brain Behav Immun 25:1223-1232.

Liu Q, Tang Z, Surdenikova L, Kim S, Patel KN, Kim A, Ru F, Guan Y, Weng HJ, Geng Y, et al. (2009) Sensory neuron-specific GPCR Mrgprs are itch receptors mediating chloroquine-induced pruritus. Cell 139:1353-1365.

Maddahi A and Edvinsson L (2010) Cerebral ischemia induces microvascular proinflammatory cytokine expression via the MEK/ERK pathway [published correction appears in $J$ Neuroinflammation (2011) 8:18]. J Neuroinflammation 7:14-26.

Medzhitov R, Preston-Hurlburt P, and Janeway CA Jr. (1997) A human homologue of the Drosophila Toll protein signals activation of adaptive immunity. Nature 388: 394-397.

Mika J, Wawrzczak-Bargiela A, Osikowicz M, Makuch W, and Przewlocka B (2009) Attenuation of morphine tolerance by minocycline and pentoxifylline in naive and neuropathic mice. Brain Behav Immun 23:75-84.

Millan MJ (1999) The induction of pain: an integrative review. Prog Neurobiol 57: $1-164$

Milligan ED, Sloane EM, and Watkins LR (2008) Glia in pathological pain: a role for fractalkine. J Neuroimmunol 198:113-120.

Ohsawa K, Irino Y, Nakamura Y, Akazawa C, Inoue K, and Kohsaka S (2007) Involvement of $\mathrm{P} 2 \mathrm{X} 4$ and $\mathrm{P} 2 \mathrm{Y} 12$ receptors in ATP-induced microglial chemotaxis. Glia 55:604-616.

Palma C, Minghetti L, Astolfi M, Ambrosini E, Silberstein FC, Manzini S, Levi G, and Aloisi F (1997) Functional characterization of substance P receptors on cultured human spinal cord astrocytes: synergism of substance $\mathrm{P}$ with cytokines in inducing interleukin-6 and prostaglandin E2 production. Glia 21:183-193.

Piccin D and Morshead CM (2011) Wnt signaling regulates symmetry of division of neural stem cells in the adult brain and in response to injury. Stem Cells 29 528-538.

Pocock JM and Kettenmann H (2007) Neurotransmitter receptors on microglia. Trends Neurosci 30:527-535.

Porter JT and McCarthy KD (1997) Astrocytic neurotransmitter receptors in situ and in vivo. Prog Neurobiol 51:439-455.

Prow NA and Irani DN (2008) The inflammatory cytokine, interleukin-1 beta, mediates loss of astroglial glutamate transport and drives excitotoxic motor neuron injury in the spinal cord during acute viral encephalomyelitis. J Neurochem 105:1276-1286.

Raghavendra V, Rutkowski MD, and DeLeo JA (2002) The role of spinal neuroimmune activation in morphine tolerance/hyperalgesia in neuropathic and shamoperated rats. J Neurosci 22:9980-9989.

Raghavendra V, Tanga FY, and DeLeo JA (2004) Attenuation of morphine tolerance, withdrawal-induced hyperalgesia, and associated spinal inflammatory immune responses by propentofylline in rats. Neuropsychopharmacology 29:327-334.

Reeve AJ, Patel S, Fox A, Walker K, and Urban L (2000) Intrathecally administered endotoxin or cytokines produce allodynia, hyperalgesia and changes in spinal cord neuronal responses to nociceptive stimuli in the rat. Eur J Pain 4:247-257.

Rönnbäck L and Hansson E (1988) Are astroglial cells involved in morphine tolerance? Neurochem Res 13:87-103.

Samad TA, Moore KA, Sapirstein A, Billet S, Allchorne A, Poole S, Bonventre JV and Woolf CJ (2001) Interleukin-1beta-mediated induction of Cox-2 in the CNS contributes to inflammatory pain hypersensitivity. Nature 410:471-475.

Serrano-Pozo A, William CM, Ferrer I, Uro-Coste E, Delisle MB, Maurage CA, Hock C, Nitsch RM, Masliah E, Growdon JH, et al. (2010) Beneficial effect of human anti-amyloid-beta active immunization on neurite morphology and tau pathology. Brain 133:1312-1327.

Shavit Y, Wolf G, Goshen I, Livshits D, and Yirmiya R (2005) Interleukin-1 antagonizes morphine analgesia and underlies morphine tolerance. Pain 115:50-59.

Shi F, Yang Y, Wang T, Kouadir M, Zhao D, and Hu S (2016) Cellular prion protein promotes neuronal differentiation of adipose-derived stem cells by upregulating miRNA-124. J Mol Neurosci 59:48-55. 
Song P and Zhao ZQ (2001) The involvement of glial cells in the development of morphine tolerance. Neurosci Res 39:281-286.

Souza GR, Talbot J, Lotufo CM, Cunha FQ, Cunha TM, and Ferreira SH (2013) Fractalkine mediates inflammatory pain through activation of satellite glial cells. Proc Natl Acad Sci USA 110:11193-11198.

Sperlágh B, Baranyi M, Haskó G, and Vizi ES (2004) Potent effect of interleukin-1 beta to evoke ATP and adenosine release from rat hippocampal slices. $J$ Neuroimmunol 151:33-39.

Tanga FY, Raghavendra V, and DeLeo JA (2004) Quantitative real-time RT-PCR assessment of spinal microglial and astrocytic activation markers in a rat model of neuropathic pain. Neurochem Int 45:397-407.

Tawfik VL, LaCroix-Fralish ML, Nutile-McMenemy N, and DeLeo JA (2005) Transcriptional and translational regulation of glial activation by morphine in a rodent model of neuropathic pain. J Pharmacol Exp Ther 313:1239-1247.

Tikka T, Fiebich BL, Goldsteins G, Keinanen R, and Koistinaho J (2001) Minocycline, a tetracycline derivative, is neuroprotective against excitotoxicity by inhibiting activation and proliferation of microglia. $J$ Neurosci 21:2580-2588.

Tsubota K, Nishiyama T, Mishima K, Inoue H, Doi T, Hattori Y, Kodama T, Higuchi A, Hayashi Y, and Saito I (2009) The role of fractalkine as an accelerating factor on the autoimmune exocrinopathy in mice. Invest Ophthalmol Vis Sci 50:4753-4760.

Tsuda M (2017) P2 receptors, microglial cytokines and chemokines, and neuropathic pain. J Neurosci Res 95:1319-1329.

Tsuda M, Shigemoto-Mogami Y, Koizumi S, Mizokoshi A, Kohsaka S, Salter MW, and Inoue K (2003) P2X4 receptors induced in spinal microglia gate tactile allodynia after nerve injury. Nature 424:778-783.

Ulmann L, Hatcher JP, Hughes JP, Chaumont S, Green PJ, Conquet F, Buell GN, Reeve AJ, Chessell IP, and Rassendren F (2008) Up-regulation of P2X4 receptors in spinal microglia after peripheral nerve injury mediates BDNF release and neuropathic pain. J Neurosci 28:11263-11268.

Verge GM, Milligan ED, Maier SF, Watkins LR, Naeve GS, and Foster AC (2004) Fractalkine (CX3CL1) and fractalkine receptor (CX3CR1) distribution in spinal cord and dorsal root ganglia under basal and neuropathic pain conditions. Eur $J$ Neurosci 20:1150-1160.

Viviani B, Bartesaghi S, Gardoni F, Vezzani A, Behrens MM, Bartfai T, Binaglia M, Corsini E, Di Luca M, Galli CL, et al. (2003) Interleukin-1beta enhances NMDA receptor-mediated intracellular calcium increase through activation of the Src family of kinases. $J$ Neurosci 23:8692-8700.

Walwyn W, Evans CJ, and Hales TG (2007) Beta-arrestin2 and c-Src regulate the constitutive activity and recycling of mu opioid receptors in dorsal root ganglion neurons. J Neurosci 27:5092-5104.

Wang D, Chen T, Zhou X, Couture R, and Hong Y (2013) Activation of Mas oncogenerelated gene $(\mathrm{Mrg}) \mathrm{C}$ receptors enhances morphine-induced analgesia through modulation of coupling of $\mu$-opioid receptor to Gi-protein in rat spinal dorsal horn. Neuroscience 253:455-464.
Wang D, Wang P, Jiang J, Lv Q, Zeng X, and Hong Y (2015) Activation of Mas oncogene-related $\mathrm{G}$ protein-coupled receptors inhibits neurochemical alterations in the spinal dorsal horn and dorsal root ganglia associated with inflammatory pain in rats. J Pharmacol Exp Ther 354:431-439.

Wang D, Xue Y, Yan Y, Lin M, Yang J, Huang J, and Hong Y (2016) Reversal of neurochemical alterations in the spinal dorsal horn and dorsal root ganglia by Masrelated gene (Mrg) receptors in a rat model of spinal nerve injury. Neurobiol Dis 91: 274-283.

Wang X, Loram LC, Ramos K, de Jesus AJ, Thomas J, Cheng K, Reddy A, Somogyi AA, Hutchinson MR, Watkins LR, et al. (2012) Morphine activates neuroinflammation in a manner parallel to endotoxin. Proc Natl Acad Sci USA 109:6325-6330.

Watkins LR, Hutchinson MR, Johnston IN, and Maier SF (2005) Glia: novel counterregulators of opioid analgesia. Trends Neurosci 28:661-669.

Watkins LR, Hutchinson MR, Rice KC, and Maier SF (2009) The "toll" of opioidinduced glial activation: improving the clinical efficacy of opioids by targeting glia. Trends Pharmacol Sci 30:581-591.

Watkins LR, Milligan ED, and Maier SF (2001) Glial activation: a driving force for pathological pain. Trends Neurosci 24:450-455.

Wu T, Dai M, Shi XR, Jiang ZG, and Nuttall AL (2011) Functional expression of P2X4 receptor in capillary endothelial cells of the cochlear spiral ligament and its role in regulating the capillary diameter. Am J Physiol Heart Circ Physiol 301:H69-H78.

Zhang D, Ma G, Hou M, Zhang T, Chen L, and Zhao C (2016) The neuroprotective effect of puerarin in acute spinal cord injury rats. Cell Physiol Biochem 39:1152-1164.

Zhu W, Acosta C, MacNeil B, Cortes C, Intrater H, Gong Y, and Namaka M (2013) Elevated expression of fractalkine (CX3CL1) and fractalkine receptor (CX3CR1) in the dorsal root ganglia and spinal cord in experimental autoimmune encephalomyelitis: implications in multiple sclerosis-induced neuropathic pain. BioMed Res Int 2013:480702.

Zhuang ZY, Wen YR, Zhang DR, Borsello T, Bonny C, Strichartz GR, Decosterd I, and Ji RR (2006) A peptide c-Jun N-terminal kinase (JNK) inhibitor blocks mechanical allodynia after spinal nerve ligation: respective roles of JNK activation in primary sensory neurons and spinal astrocytes for neuropathic pain development and maintenance. $J$ Neurosci 26:3551-3560.

Zimmermann M (1983) Ethical guidelines for investigations of experimental pain in conscious animals. Pain 16:109-110.

Zylka MJ, Dong X, Southwell AL, and Anderson DJ (2003) Atypical expansion in mice of the sensory neuron-specific Mrg G protein-coupled receptor family. Proc Nat Acad Sci USA 100:10043-10048.

Address correspondence to: Dr. Yanguo Hong, College of Life Sciences, Fujian Normal University, Fuzhou, Fujian 350117, China. E-mail: yhong@fjnu. edu.cn 